\title{
The Global Spine Care Initiative: resources to implement a spine care program
}

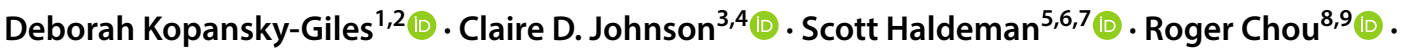

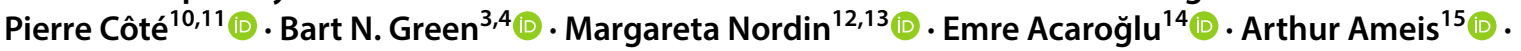

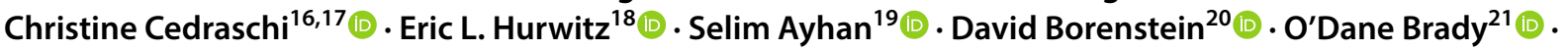 \\ Peter Brooks ${ }^{22} \cdot$ Fereydoun Davatchi ${ }^{23}$ (1) Robert Dunn ${ }^{24,25}$ (C) Christine Goertz ${ }^{26,27}$ (1) Najia Hajjaj-Hassouni ${ }^{28}$ (1) \\ Jan Hartvigsen ${ }^{29,30}$ - Maria Hondras $s^{31}$. Nadège Lemeunier ${ }^{32} \cdot$ John Mayer $^{33} \cdot$ Silvano Mior $^{34}\left(\mathbb{0}\right.$. Jean Moss ${ }^{35}$. \\ Rajani Mullerpatan ${ }^{36}$. Elijah Muteti ${ }^{37} \cdot$ Lillian Mwaniki $^{38} \cdot$ Madeleine Ngandeu-Singwe $^{39} \cdot$ Geoff Outerbridge $^{40}$ (1) \\ Kristi Randhawa $^{10,11}$ [D $\cdot$ Carlos Torres $^{41,42} \cdot$ Paola Torres $^{43} \cdot$ Adriaan Vlok $^{44} \cdot$ Chung Chek Wong $^{45}$
}

Received: 12 April 2018 / Accepted: 6 August 2018 / Published online: 27 August 2018

(c) The Author(s) 2018

\begin{abstract}
Purpose The purpose of this report is to describe the development of a list of resources necessary to implement a model of care for the management of spine-related concerns anywhere in the world, but especially in underserved communities and low- and middle-income countries.

Methods Contents from the Global Spine Care Initiative (GSCI) Classification System and GSCI care pathway papers provided a foundation for the resources list. A seed document was developed that included resources for spine care that could be delivered in primary, secondary and tertiary settings, as well as resources needed for self-care and community-based settings for a wide variety of spine concerns (e.g., back and neck pain, deformity, spine injury, neurological conditions, pathology and spinal diseases). An iterative expert consensus process was used using electronic surveys.

Results Thirty-five experts completed the process. An iterative consensus process was used through an electronic survey. A consensus was reached after two rounds. The checklist of resources included the following categories: healthcare provider knowledge and skills, materials and equipment, human resources, facilities and infrastructure. The list identifies resources needed to implement a spine care program in any community, which are based upon spine care needs.

Conclusion To our knowledge, this is the first international and interprofessional attempt to develop a list of resources needed to deliver care in an evidence-based care pathway for the management of people presenting with spine-related concerns. This resource list needs to be field tested in a variety of communities with different resource capacities to verify its utility.
\end{abstract}

Graphical abstract These slides can be retrieved under Electronic Supplementary Material.
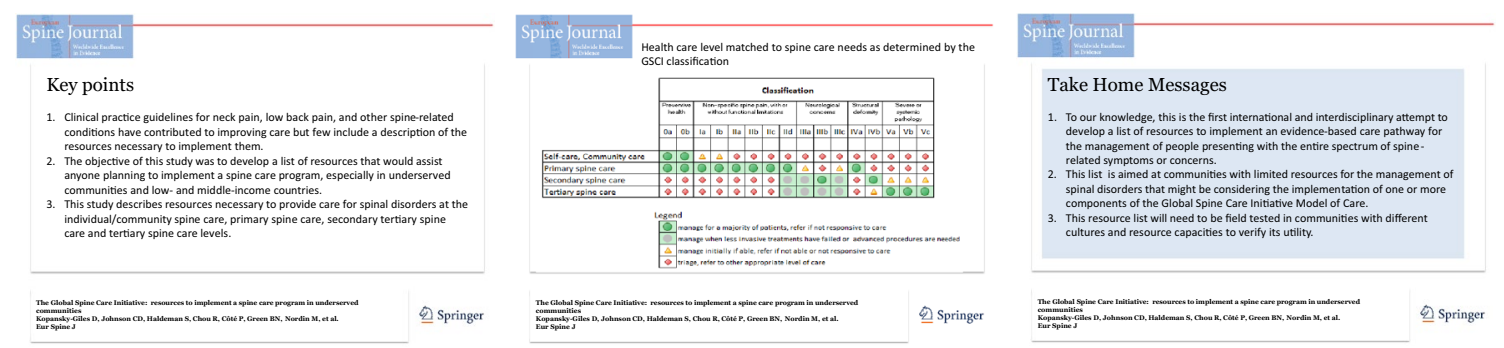

Electronic supplementary material The online version of this article (https://doi.org/10.1007/s00586-018-5725-7) contains supplementary material, which is available to authorized users.

Extended author information available on the last page of the article 
Keywords Health resources $\cdot$ Delivery of health care $\cdot$ Integrated $\cdot$ Primary health care

\section{Introduction}

Clinical practice guidelines for neck, low back pain and other spine-related conditions may contribute to improving quality of care but have limited discussions about resource recommendations for specific interventions. Guidelines must describe the resources that are needed to provide spine care in any community where high-quality, resource-efficient health care is going to be implemented. This is especially important for communities that have limited resources, such as in low- and middle-income communities.

The importance of capacity assessment models and human resource distribution has been described by the World Health Organization and the United Nations Development Programme [1, 2]. However, these documents do not provide how to integrate specific health resources such as knowledge and skills, materials and equipment, human resources, facilities and infrastructure into their frameworks [1,2]. There has been increased interest in addressing human health resources and infrastructure necessary to provide universal, general health care and for specific health conditions [3, 4]. However, to our knowledge, no comprehensive description of resource capacity required to deliver evidence-based care for spine-related disorders has been published.

The Global Spine Care Initiative (GSCI) has developed a model of spine care that is based on the GSCI classification system and care pathway, and foundational papers [5-18]. The GSCI model of care has been developed so that it could be implemented in different settings with variable levels of health and community resources. Before considering the implementation of a model of care in a community, however, it is essential to identify both available and required resources required to provide the recommended services. The objectives of this study were to develop a list of resources to implement a program to provide care for spinerelated disorders at the community, primary, secondary and tertiary levels. The aim was to provide a list of resources that could be used in any location, but that could also be implemented in resource-poor settings such as underserved areas and low- and middle-income communities.

\section{Methods}

The GSCI, an interprofessional and international team of spine experts, developed a spine classification system, care pathway and model of care. These methods are described in detail elsewhere $[5-7,17]$. Based on the information contained in these papers, resources that were required to implement a spine care program were thematically organized into categories: (1) healthcare provider skills and knowledge, (2) materials and equipment, (3) human resources, (4) facilities and infrastructure. These four categories are considered applicable to the provision of evidence-based spine care in communities with a wide range of resource levels. A seed document was created with the categories and example resources. Consideration was given to the resources that would be needed to deliver the assessments and interventions described in the care pathway, matched to classification level. Participants were invited to review the seed document and provide input through Survey Monkey (SurveyMonkey Inc., San Mateo, California, USA). The information from each round was added to the list of resources, and a consensus was reached on the resources list after two rounds.

A diverse group of international and interprofessional experts, clinicians, and patient advocates were identified and invited to review the seed document [17]. The participants represented different geographic regions and a wide range of professional roles and organization types from across the continuum of care. The National University of Health Sciences (Lombard, IL, USA) Institutional Review Board approved this process (\#H-1503). Informed consent was obtained from each participant.

Each class described in the GSCI classification system was matched to a proposed level of care (self/community, primary, secondary, tertiary) determined from the evidencebased recommendations in the GSCI care pathway. The match was done with the assumption that ideal circumstances exist or could be found. This match also assumed that the person/providers at each level of care has, or has access to, the knowledge and skills to provide all necessary assessments and interventions for each of the classes.

A checklist of resources was created for each of the four categories: healthcare provider skills and knowledge, materials and equipment, human resources, facilities and infrastructure. For the first round, the seed document was sent to participants. Each person who accepted the invitation provided input to the document. The document was revised, and the revision was redistributed for additional consideration and input. All items with no change requests were classified as an agreement. The document was revised further, and the final draft was agreed upon by all coauthors. 


\section{Results}

Invitations for the first survey were sent to 43 people who were previously identified as GSCI participants. From the first invitation, 40 responded, of these five indicated that they did not wish to participate. This resulted in 35 participants from 15 countries (Australia, Cameroon, Canada, Chile, Denmark, France, India, Iran, Kenya, Malaysia, Morocco, South Africa, Switzerland, Turkey and USA) who contributed to the development of this resources document. The healthcare level was matched to the spine care needs (Fig. 1).

The resource spreadsheet is organized into four categories (i.e., knowledge and skills, materials and equipment, human resources, facility and infrastructure) and matched with the classes of spine concerns [5]. This chart identifies what resources are necessary to deliver care to match community spine care needs based upon the various levels of available care (self-care/community care, primary spine care, secondary spine care, tertiary spine care) and the disorders that are prevalent in the community. The resource categories were confirmed through the consensus process (see Online Resource Table 1).

\section{Discussion}

This paper assesses the resources necessary to implement a proposed care pathway for the management of the entire spectrum of spinal disorders which could be used to inform the implementation of a model of care in communities which do not have established spine care programs. This description of resources was developed with the goal of avoiding many of the concerns that have been raised about the provision of spine care in high-income, high-resource countries which have seen a marked increase in the cost of providing care without any evident reduction in spine-related disability [19-23]. The hope is to avoid the increasing use of highcost, high-tech passive interventions which have become an increasing component of spine care in high-income countries and which have not been shown to have a major impact on spine-related disability [24]. This article identifies the resources necessary to achieve an evidence-based spine care delivery system which is patient-centered and takes into account the patient and community needs and priorities [25].

There is little information in the peer-reviewed literature that addresses the resources necessary to implement a model of care for the management of spinal disorders. Extensive work has been done in Australia to propose a model of care for musculoskeletal disorders that relies on multidisciplinary teams [26]. However, the authors do not describe the resources necessary to implement the model. It is therefore necessary to visit the literature on resource determination for general health or other specific disease categories when considering the reasonableness of the categories used in this survey.

We have attempted to apply examples from other fields to address the needs in our study. One example of a toolbox comes from the Center for Community Health and Development at the University of Kansas (https://ctb.ku.edu/en). They describe the importance of assessing the needs and resources to improve health care in their communities in the most logical and efficient manner. Their toolbox describes assets that include individuals, organizations and institutions, buildings, landscapes and equipment and is consistent with the survey used in this study.

Other examples include human resources and models of mental healthcare integration into primary and community care in India that may be helpful in providing additional insight. Solutions to address the scarcity of mental healthcare specialists in India included the development of diverse community mental healthcare models, specific to the local context. These models emphasized the importance of community-based primary mental health caregivers who work closely with specialists for the most ill patients. The model provided in the India context has similarities to the model being proposed for spine care [27]. The WHO undertook a survey to assess the capacity of Member States to develop and implement programs that focused on addressing hearing loss. The lack of human, financial and educational resources were identified as significant barriers to implementing programs and policies necessary to address the needs of people with hearing loss [28]. The WHO found that $28 \%$ of countries facilitated delivery of hearing programs through collaboration with other government agencies, healthcare groups, funding resources, nongovernmental organizations and professional bodies. Spine care in poorly resourced settings may be similarly aided by sharing of resources or by supplementing existing healthcare facilities, infrastructure, human and funding resources [27, 29].

We have proposed four categories of resources to deliver spine care in addition to funding availability. We make the assumption that funding is a critical resource across all settings and do not specifically address it in this manuscript. These resource categories include knowledge and skills, materials and equipment, human resources and facilities and infrastructure. The respondents to the survey in this article clearly articulated that the type of resources required to provide care is dependent on the nature or class of spinal disorders that are to be managed in a specific setting. It is crucial to take into account the resources that are already present in the target community [8]. Based on the resources identified, we developed a practical checklist (see Online Resource Table 2). The checklist should assist anyone planning to implement a spine care programs in 


\begin{tabular}{|c|c|c|c|c|c|c|c|c|c|c|c|c|c|c|c|c|}
\hline & \multicolumn{16}{|c|}{ Classification } \\
\hline & \multicolumn{2}{|c|}{$\begin{array}{c}\text { Preventive } \\
\text { health }\end{array}$} & \multicolumn{6}{|c|}{$\begin{array}{l}\text { Non-specific spine pain, with or } \\
\text { without functional limitations }\end{array}$} & \multicolumn{3}{|c|}{$\begin{array}{l}\text { Neurological } \\
\text { concerns }\end{array}$} & \multicolumn{2}{|c|}{\begin{tabular}{|l|} 
Structural \\
deformity
\end{tabular}} & \multicolumn{3}{|c|}{$\begin{array}{l}\text { Severe or } \\
\text { systemic } \\
\text { pathology }\end{array}$} \\
\hline & $0 a$ & $\mathrm{Ob}$ & la & $\mathrm{Ib}$ & Ila & $\mathrm{Ilb}$ & IIC & IId & IIIa & $111 \mathrm{~b}$ & IIIC & IVa & IVb & $\mathrm{Va}$ & $\mathrm{Vb}$ & Vc \\
\hline Self-care, Community care & 0 & 0 & $\Delta$ & $\triangle$ & $\diamond$ & 0 & $\diamond$ & $\diamond$ & $\diamond$ & $\diamond$ & $\diamond$ & $\diamond$ & $\diamond$ & $\diamond$ & $\diamond$ & $\Delta$ \\
\hline Primary spine care & O & 0 & O & O & 0 & 0 & 0 & 0 & $\triangle$ & $\diamond$ & $\triangle$ & 0 & $\diamond$ & $\diamond$ & $\diamond$ & $\diamond$ \\
\hline Secondary spine care & $\diamond$ & $\diamond$ & $\diamond$ & $\diamond$ & $\diamond$ & $\diamond$ & $\diamond$ & (1) & 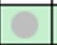 & 0 & (1) & $\diamond$ & 0 & $\triangle$ & $\triangle$ & $\triangle$ \\
\hline Tertiary spine care & 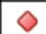 & $\diamond$ & $\Delta$ & $\Delta$ & 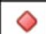 & 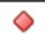 & 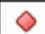 & P & ? & 0 & $\mathrm{P}$ & $\diamond$ & $\Delta$ & 0 & 0 & 0 \\
\hline
\end{tabular}

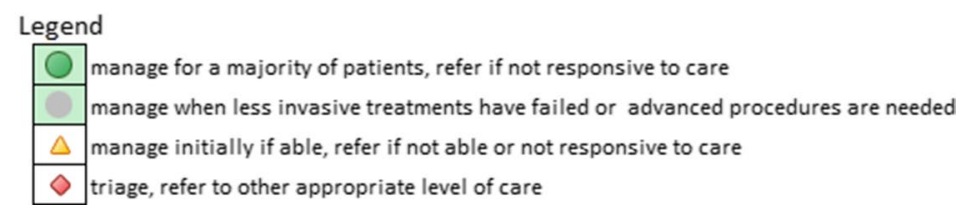

- Self-care resources support care that is done by the individual or caregivers and includes self-management of symptoms and prevention activities at home or at work. Resources support the individual with the spine concern, family members, and the social network as first direct caregivers.

- Community care resources support care at the community level, public health workers, and other first contact health care professionals. Resources support public health workers who focus on evidence-based education about spine symptoms including prognosis, self-care, and prevention of disability.

- $\quad$ Primary spine care resources support primary care settings and providers who have specific knowledge and skills in evidence-based spine care. These resources support primary spine care provider integration into the health care delivery and the clinics, hospital, or ambulatory care facilities.

- Secondary spine care resources support health care specialists who have training in evidence-based care for spinal disorders requiring additional or advanced imaging and other diagnostic testing and acute emergency care or short-term invasive procedures. These resources support spine trauma management, invasive procedures such as non-complex surgery, injections and advanced pharmaceuticals. Resources include psychological or social interventions that are not available at the primary spine care level.

- Tertiary spine care resources support providers with advanced specialty and subspecialty training. Resources include support for advanced spine surgery, complex interdisciplinary and subspecialty care in systemic and inflammatory disorders. Tertiary care resources require advanced equipment, infrastructure and personnel to support these procedures. Quaternary care is an extension of tertiary care that includes experimental medicine, uncommon advanced diagnostic or surgical procedures, is highly specialized, and not widely accessed. Tertiary and quaternary care is the most resource-intensive types of care.

\section{Classification Legend}

These classes represent all potential types of spine-related concerns that could be found within a community. Each community is different and therefore may have a different proportion of spine care needs resulting in unique resource needs. For example, a community that has a high amount of spine trauma may need more resources to address Class V spine concerns. Whereas a community that has a large number of people with chronic spine pain, may need more resources to address Class II concerns. Resources should be developed based on need.

\begin{tabular}{|l|l|}
\hline \multicolumn{1}{|c|}{ Class } & \multicolumn{1}{c|}{ Subclass } \\
\hline $\begin{array}{l}\text { Class 0: No or minimal spine-related symptoms, no interference } \\
\text { with function, no neurological deficits, no severe pathology }\end{array}$ & $\begin{array}{l}\text { Class 0a: No evident risk factors } \\
\text { Class 0b: One or more risk factors }\end{array}$ \\
\hline $\begin{array}{l}\text { Class I: Mild pain, no or minimal interference with function, no } \\
\text { neurological deficits, no severe pathology }\end{array}$ & $\begin{array}{l}\text { Class Ia: Acute or subacute } \\
\text { Class Ib: Chronic or recurrent }\end{array}$ \\
\hline $\begin{array}{l}\text { Class II: Moderate or severe pain, interference with function or } \\
\text { activities of daily living, no neurological deficits, no severe } \\
\text { pathology }\end{array}$ & $\begin{array}{l}\text { Class IIa: Moderate acute or subacute pain } \\
\text { Class IIb: Moderate chronic or recurrent pain } \\
\text { Class IIc: Severe acute or subacute pain } \\
\text { Class IId: Severe chronic or recurrent pain }\end{array}$ \\
\hline $\begin{array}{l}\text { Class III: Spine-related symptoms with neurological symptoms or } \\
\text { deficits, interference with function or activities of daily living, } \\
\text { focal pathology compromising neural structures }\end{array}$ & $\begin{array}{l}\text { Class IIIa: Minor and non-progressive } \\
\text { Class IIIb: Acute, major and progressive } \\
\text { Class IIIc: Chronic and stable }\end{array}$ \\
\hline $\begin{array}{l}\text { Class IV: Spine-related symptoms with stable, severe deformity, } \\
\text { with or without interference with function or activities of daily } \\
\text { living, with or without neurological deficits }\end{array}$ & $\begin{array}{l}\text { Class IVa: Stable spine deformity no correlation with symptoms } \\
\text { Class IVb: Symptoms related to pathology (eg acute, fracture; } \\
\text { chronic, scoliosis or instability) }\end{array}$ \\
\hline $\begin{array}{l}\text { Class V: Serious spine-related symptoms with severe or systemic } \\
\text { pathology, interference with function or activities of daily living, } \\
\text { with or without neurological deficits }\end{array}$ & $\begin{array}{l}\text { Class Va: Severe, acute spinal pathology (emergency) } \\
\text { Class Vb: Severe, slowly progressive spinal pathology (non- } \\
\text { emergency) } \\
\text { Class Vc: Spine symptoms originating from non-spine pathology } \\
\text { (emergency) }\end{array}$ \\
& \\
\hline
\end{tabular}

Fig. 1 Healthcare resources matched to the GSCI classification. Republished with permission from World Spine Care 
their local communities. The checklist may also be used when assessing existing resources and to provide information on what additional resources are necessary to provide a specific level of spine care.

For the majority of patients with spine-related concerns as found in Class 0, I, II, low levels of resources need to be provided in the form of facilities and equipment and emphasis should be placed on knowledge and skills of healthcare providers. In these settings, an emphasis on clinical training of evidence-based interventions appears to be the primary resource which is required. High levels of resources are required for only a few patients with spine-related complaints who have severe disorders (Class $\mathrm{IVb}$ and Class V).

\section{Community-based and self-care}

The GSCI articles on noninvasive care, public health and psychosocial interventions recommend an emphasis on selfcare and community-based care $[11,13,18]$, which may be achieved through education to avoid misunderstanding of the prognosis and catastrophizing of spine pain. Education and prevention is a component of spine care that is often emphasized in guidelines but is difficult to put into practice. This is especially true if providers in low- and middle-income countries spend only a few minutes with each patient [30]. A study in rural South Africa noted that the community was not involved in healthcare management for most health issues, nor were users involved in their personal health management [31]. It is probable that any movement for community-based and self-care management of spinal disorders would fall on the shoulders of the primary spine care providers unless it is possible to persuade government agencies to consider a program within their public health resource budget [22].

\section{Primary spine care}

In the GSCI model of care, primary spine care is delivered by healthcare providers with training and skills in evidencebased spine care [7]. This is consistent with the recommendations of others who have looked at the skills required to manage patients with nonspecific spine pain [32, 33]. Necessary skills include the initial assessment of patients, triage for red flags suggestive of serious pathology, documentation of psychological or social flags and the management of patients with nonspecific pain and related disability (Class I and II) $[11,18]$. The latter would include patient and community education and noninvasive, low technology, lowcost interventions for symptom relief. Primary spine care providers would be responsible for referral and coordinating care for complex spinal disorders that may require secondary and tertiary spine care interventions (Class III, IV and V). It is expected that primary spine care clinicians would provide community-based information and encourage self-care when that is the most appropriate care (Class 0, I).

Primary spine care services can be provided by a single clinician or a team of clinicians, who, in combination, possess the knowledge and skills to provide evidence-based spine care [7]. In many settings, the only available clinicians are primary general care providers such as family physicians who have limited understanding of current evidencebased recommendations for patients with spinal disorders. This knowledge gap in spine care is the "ignorance of or unwillingness to follow evidence-based practice recommendations" [34]. Increased training of primary general care clinicians in spine care might be a solution. This requires an educator who understands current guidelines. This education responsibility logically would fall within the domain of the primary spine care clinician. This, however, is not always feasible. Unfortunately, for $50 \%$ of the global population, primary general care medical physicians spend 5 minutes or less with their patients [30]. By having a primary spine care clinician present, the general primary care provider could be more available to attend to other health concerns.

\section{Secondary spine care}

Secondary care is often provided at the district hospital level and includes emergency care, some diagnostic imaging and laboratory testing, inpatient and surgical facilities. Secondary care is considerably more expensive and resource intensive than primary care [35, 36]. Providers at the secondary spine care level tend to have specialist training but not subspecialty training. Secondary spine care services typically include short-term interventions that require one or more of the following: acute trauma and emergency care, hospitalization, routine surgery, consultation, injections, and rehabilitation. Ideally, the resources to provide psychological and social interventions, as well as some level of pharmaceutical care and spine surgery, would exist in this setting.

Secondary spine care is accessed typically through a referral from a primary spine care provider. In order to be utilized efficiently, only patients requiring care not available at the primary spine care level should be seen in the secondary spine care setting. In addition, when the secondary spine care intervention is completed, the patient should be referred back to the primary spine care setting for ongoing care if indicated. This would avoid stressing the resources at the secondary care level when care can be provided at the primary care level. 


\section{Tertiary and quaternary spine care}

Tertiary spine care is specialized medical and surgical care for complex, serious and unusual spinal disorders that cannot be managed at the primary or secondary spine care levels. This level of care requires the highest level of resources and is commonly carried out in large inpatient hospitals [37]. Care is provided primarily by clinicians with subspecialty training in such fields as rheumatology, neurology, infectious disease, oncology and most internal medicine subspecialties as recommended in the GSCI care pathway for Class $\mathrm{V}$ diseases [6]. The tertiary spine care setting would also require surgeons with advanced spine surgical skills and the supporting surgical infrastructure and personnel to manage the most complex surgical procedures that may be necessary to address severe spine trauma and deformity (Class IVb) and destructive spine pathology (Class V). Typically, tertiary care facilities have advanced diagnostic equipment and intensive care units. Tertiary spine care should also have the resources to manage cases of chronic incapacitating spine pain that have been unresponsive to primary and secondary spine care. This may require resources such as advanced pharmaceuticals, psychological, surgery or multidisciplinary cognitive-behavioral care. In some cases, patients may require treatment for co-morbidities or health conditions that are related to but not generated from the spine.

Beyond tertiary is quaternary care, which is the most resource intense and complex level of surgical and medical care available. Quaternary care is provided at university or research institutions, typically utilizing experimental procedures. Quaternary care is rarely found in low-income countries and therefore may be a low priority. The care provided at the tertiary spine care level requires the highest resource intensity and should be limited to those few cases which cannot be managed at the primary and secondary spine care levels. The inappropriate referral to tertiary care can result in significant and unnecessary excessive cost and use of resources associated with such referrals [38].

\section{Optimization and integration of spine care with existing resources}

Developing countries face the challenge of immense needs for health services dwarfing the limited resources available in already overloaded and fragile systems. Twenty criteria have been proposed to assist with decision making around how to best use these limited resources [39]. Similar to the resource needs identified in the GSCI model, a number of these twenty criteria focus on the characteristics of the healthcare provider delivering care. In the GSCI model, knowledge and skills are considered the most important resources to provide care. The collaborative, interprofessional care in high-income countries has a number of benefits that may be useful in clinics with fewer resources. Interprofessional care has been associated with increased quality of care and indicators of safety [40] as well as improved clinical efficiency, improved skills, greater levels of responsiveness, more holistic services and higher levels of innovation and creativity [41, 42]. WHO has identified that interprofessional practice is associated with better outcomes in family health, infectious disease, humanitarian efforts and noncommunicable diseases [43]. In addition, improved outcomes in chronic diseases have been associated with interprofessional care [40].

For example, in Canada, there were long wait times for advanced diagnostic imaging and specialist care, rising costs and no improvement in patient outcomes for low back pain. A primary care spine-focused clinical assessment program was piloted that showed that for those receiving regular care, $100 \%$ of computed tomography and $60 \%$ of magnetic resonance imaging were unnecessary and did not improve clinical outcomes [44]. However, patients who received primary care level management had improved outcomes and cost savings. If primary spine care could be engaged earlier, wait lists and access to specialty services may be alleviated and this would ensure appropriate allocation of resource utilization. Educating the primary care health workforce to provide primary care spine-focused assessments may help in resource-poor communities to ensure that the available infrastructure and resources have the greatest impact [45].

Another example is the World Spine Care program in Botswana that identified challenges of establishing clinical facilities in a poorly resourced community. In collaboration with the Botswana Ministry of Health, World Spine Care developed a primary spine care clinic in a rural community by adapting a facility provided by the government. This allowed for the delivery of spine care with few physical resources. In this community, the most important factor was a primary care clinician trained in evidence-based spine care. This allowed for the provision of spine care locally without having to refer people with common spine-related complaints to secondary or tertiary facilities. Primary spine care delivery provided community-based education including exercise programs and the referral of patients to the regional district hospital for imaging, laboratory and medical services not available at the community clinic [46]. The success of implementing this primary spine care clinic resulted in a request for implementation of a second clinic in the district hospital outpatient setting. These experiences have demonstrated that the spine care needs of a community can be adapted to resources as they become available and integrated into existing health structures. 


\section{Limitations}

Our findings are based upon expert consensus informed by the GSCI evidence-based studies in addition to practical experience. Limitations include that not all of the 68 GSCI experts participated in the development of the care pathway and therefore may be subject to bias. The resource list will need to be evaluated in various communities with different levels of resources and cultures to determine whether the information is practical and if the categories are properly aligned with the classification and care pathway. As the model of care is implemented in different communities, it is likely that the resource checklist will evolve and improve based upon feedback from the field. This is not an all-inclusive list, and there are likely resources that need to be added depending upon the region. The resource list is an evolving process, and the checklists will evolve as the model is tested.

\section{Conclusion}

To our knowledge, this is the first international and interprofessional attempt to develop a list of resources needed to deliver care in an evidence-based care pathway for the management of people presenting with the entire spectrum of spine-related concerns. This resource list will need to be field tested in a variety of communities with different resource capacities to verify its utility.

Funding The Global Spine Care Initiative and this study were funded by grants from the Skoll Foundation and NCMIC Foundation. World Spine Care provided financial management for this project. The funders had no role in study design, analysis or preparation of this paper.

\section{Compliance with ethical standards}

Conflicts of interest DKG declares travel expenses: CMCC to present at the WSC Spine Conference in Botswana. CDJ is president of Brighthall, Inc.; she is an NCMIC Board of Director; however, neither she nor NCMIC board make funding decisions for the NCMIC Foundation; the views in this article are those of the authors and not those of Stanford University, Stanford Health Care or Qualcomm. SH declares funding to UOIT from Skoll Foundation, NCMIC Foundation through World Spine Care; Clinical Policy Advisory Board and stock holder, Palladian Health; Advisory Board, SpineHealth.com; Book Royalties, McGraw Hill. Travel expense reimbursement-CMCC Board. RC declares funding from AHRQ to conduct systematic reviews on treatments for low back pain within last 2 years. Honoraria for speaking at numerous meetings of professional societies and nonprofit groups on topics related to low back pain (no industry sponsored talks). PC is funded by a Canada Research Chair in Disability Prevention and Rehabilitation at the University of Ontario Institute of Technology and declares funding to UOIT from Skoll Foundation, NCMIC Foundation through World Spine Care. Canadian Institutes of Health Research Canada. Research Chair Ontario Ministry of Finance. Financial Services Commission of Ontario. Ontario Trillium Foundation, ELIB Mitac. Fond de Recherche and Sante du Quebec. BNG receives speaker fees and travel reimbursement from NCMIC Speakers' Bureau; he is secretary of Brighthall, Inc.; the views in this article are those of the authors and not those of Stanford University, Stanford Health Care or Qualcomm. MN declares funding from Skoll Foundation and NCMIC Foundation through World Spine Care. Co-Chair, World Spine Care Research Committee. Palladian Health, Clinical Policy Advisory Board member. Book Royalties Wolters Kluwer and Springer. Honoraria for speaking at research method courses. EAc declares grants: Depuy Synthes Spine, Medtronic; Speaker's bureau: AOSpine, Zimmer Biomet. EH declares he is a consultant for: RAND Corporation; EBSCO Information Services; Southern California University of Health Sciences; Western University of Health Sciences Data and Safety Monitoring Committee. Chair, Palmer Center for Chiropractic Research. Research Committee Co-chair, World Spine Care. OB declares he is a consultant for: Pacira Pharmaceuticals, Inc. Palladian Health. Travel expenses: World Spine Care. Stipend: World Spine Care. PB declares contribution to salary for Global Musculoskeletal Alliance (G-MUSC), The Bone and Joint Decade work. CG declares travel expenses: Palmer College to GSCI meetings. Consultant: American Chiropractic Association, Spine IQ, Healthwise, Quality Insights of Pennsylvania, RAND Co.; Prezacor, Inc. (Stock Options). PCORI (Board Member). Grants: Collaborative Care for Veterans with Spine pain and Mental Health Issues. NIH/Kiernan Chiropractic Care in Rehabilitation at Crotched Mountain: Crotched Mountain Private Sector Integrated Chiropractic Study N/A. NCMIC Foundation Chiropractic services, Assessment of Chiropractic Treatment for Low Back Pain; RAND Subcontract, Department of Defense Prime Award \#W81XWH-11-2-017 Sub \#9920110071. JH declares his research group has extensive funding from Danish public funding agencies, the European Union and Danish charities. MH declares travel support from World Spine Care. JM declares general research resources from USF Research Center. Research grants from funding agencies: FEMA, US Department of Homeland Security (EMW-2013-FP-00723). Palladian Health Advisory Board: Clinical Policy and Advisory Board. Intellectual property rights: Inventor of Web-based system to deliver exercise (Employer-USF: copyright holder). JM declares WSC Board Member. EM declares AO Spine Africa Faculty courses-honorarium. GO declares he is a consultant and receives travel support as Clinic Director, World Spine Care. KR declares funding to UOIT from Skoll Foundation, NCMIC Foundation through World Spine Care. Remaining authors declare that they have no conflict of interest.

Open Access This article is distributed under the terms of the Creative Commons Attribution 4.0 International License (http://creativeco mmons.org/licenses/by/4.0/), which permits unrestricted use, distribution, and reproduction in any medium, provided you give appropriate credit to the original author(s) and the source, provide a link to the Creative Commons license, and indicate if changes were made.

\section{References}

1. WHO (2016) Global strategy on human resources for healthWorkforce 2030 —WHO.pdf. pp 1-64

2. UNDP CDG (2007) Capacity Assessment Methodology User's Guide, pp 1-77

3. MONDKAL (2012) Human Resources for Health (HRH) Assessment in Northern Kenya: an overview of health workforce distribution across 10 counties. Nairobi, MONDKAL. http://www. health.go.ke/wp-content/uploads/2015/09/Final $\% 20$ merged $\% 20$ NK\%20HRH\%20Report.pdf

4. Del CAG, Rodríguez BM, González JDC, Carballo C, Bibiano CG, Artillo S et al (2017) Physical structure, human resources, and health care quality indicators in public hospital emergency 
departments in the autonomous communities of Madrid and Catalonia: a comparative study. Emergencias: revista de la Sociedad Espanola de Medicina de Emergencias 29(6):373-383

5. Haldeman S, Johnson CD, Chou R, Nordin M, Côté P, Hurwitz EL et al (2018) The Global Spine Care Initiative: classification system for spine-related concerns. Eur Spine J. https://doi.org/10.1007/ s00586-018-5724-8

6. Haldeman S, Johnson CD, Chou R, Nordin M, Côté P, Hurwitz EL et al (2018) The Global Spine Care Initiative: care pathway for people with spine-related concerns. Eur Spine J. https://doi. org/10.1007/s00586-018-5721-y

7. Johnson CD, Haldeman S, Chou R, Nordin M, Green BN, Côté P, Hurwitz EL et al (2018) The Global Spine Care Initiative: model of care and implementation. Eur Spine J. https://doi.org/10.1007/ s00586-018-5720-z

8. Acaroglu E, Mmopelwa T, Yuksel S, Ayhan S, Nordin M, Randhawa K et al (2017) The Global Spine Care Initiative: a consensus process to develop and validate a stratification scheme for surgical care of spinal disorders as a guide for improved resource utilization in low- and middle-income communities. Eur Spine J. https ://doi.org/10.1007/s00586-017-5332-z

9. Acaroglu E, Nordin M, Randhawa K, Chou R, Cote P, Mmopelwa $T$ et al (2017) The Global Spine Care Initiative: a summary of guidelines on invasive interventions for the management of persistent and disabling spinal pain in low- and middle-income communities. Eur Spine J. https://doi.org/10.1007/s00586-017-5392-0

10. Ameis A, Randhawa K, Yu H, Cote P, Haldeman S, Chou R et al (2017) The Global Spine Care Initiative: a review of reviews and recommendations for the non-invasive management of acute osteoporotic vertebral compression fracture pain in low- and middle-income communities. Eur Spine J. https://doi.org/10.1007/ s00586-017-5273-6

11. Cedraschi C, Nordin M, Haldeman S, Randhawa K, KopanskyGiles D, Johnson CD et al (2017) The Global Spine Care Initiative: a narrative review of psychological and social issues in back pain in low- and middle-income communities. Eur Spine J. https ://doi.org/10.1007/s00586-017-5434-7

12. Chou R, Cote P, Randhawa K, Torres $\mathrm{P}, \mathrm{Yu} \mathrm{H}$, Nordin $\mathrm{M}$ et al (2017) The Global Spine Care Initiative: applying evidence-based guidelines on the non-invasive management of back and neck pain to low- and middle-income communities. Eur Spine J. https://doi. org/10.1007/s00586-017-5433-8

13. Green BN, Johnson CD, Haldeman S, Kane EJ, Clay MB, Griffith E et al (2018) The Global Spine Care Initiative: public health and prevention interventions for common spine disorders in low- and middle-income communities. Eur Spine J. https://doi.org/10.1007/ s00586-018-5635-8

14. Haldeman S, Nordin M, Chou R, Côté P, Hurwitz EL, Johnson CD, Randhawa $\mathrm{K}$ et al (2018) The Global Spine Care Initiative: World Spine Care executive summary on reducing spine-related disability in low- and middle-income communities. Eur Spine J. https://doi.org/10.1007/s00586-018-5722-x

15. Hurwitz EL, Randhawa K, Torres P, Yu H, Verville L, Hartvigsen J et al (2017) The Global Spine Care Initiative: a systematic review of individual and community-based burden of spinal disorders in rural populations in low- and middle-income communities. Eur Spine J. https://doi.org/10.1007/s00586-017-5393-z

16. Hurwitz EL, Randhawa K, Yu H, Cote P, Haldeman S (2017) The Global Spine Care Initiative: a summary of the global burden of low back and neck pain studies. Eur Spine J. https://doi. org/10.1007/s00586-017-5432-9

17. Johnson CD, Haldeman S, Nordin M, Chou R, Côté P, Hurwitz EL et al (2018) The Global Spine Care Initiative: methodology, contributors, and disclosures. Eur Spine J. https://doi.org/10.1007/ s00586-018-5723-9
18. Nordin M, Randhawa K, Torres P, Yu H, Haldeman S, Brady O et al (2017) The Global Spine Care Initiative: a systematic review for the assessment of spine-related complaints in populations with limited resources and in low- and middle-income communities. Eur Spine J. https://doi.org/10.1007/s00586-017-5446-3

19. Martin BI, Deyo RA, Mirza SK, Turner JA, Comstock BA, Hollingworth W et al (2008) Expenditures and health status among adults with back and neck problems. JAMA 299(6):656-664

20. Martin BI, Turner JA, Mirza SK, Lee MJ, Comstock BA, Deyo RA (2009) Trends in health care expenditures, utilization, and health status among US adults with spine problems, 1997-2006. Spine (Phila Pa 1976) 34(19):2077-2084

21. Dagenais S, Caro J, Haldeman S (2008) A systematic review of low back pain cost of illness studies in the United States and internationally. Spine J 8(1):8-20

22. Buchbinder R, van Tulder M, Öberg B, Costa LM, Woolf A, Schoene M et al (2018) Low back pain: a call for action. Lancet 391(10137):2384-2388

23. Foster NE, Anema JR, Cherkin D, Chou R, Cohen SP, Gross DP et al (2018) Prevention and treatment of low back pain: evidence, challenges, and promising directions. Lancet 391(10137):2368-2383

24. Freburger JK, Holmes GM, Agans RP, Jackman AM, Darter JD, Wallace AS et al (2009) The rising prevalence of chronic low back pain. Arch Intern Med 169(3):251-258

25. Chou L, Ranger TA, Peiris W, Cicuttini FM, Urquhart DM, Sullivan K et al (2018) Patients' perceived needs of healthcare providers for low back pain management: a systematic scoping review. Eur Spine J. https://doi.org/10.1007/s00586-017-5433-8

26. Slater H, Briggs AM (2017) Models of care for musculoskeletal pain conditions: driving change to improve outcomes. Fut Med 7(5):351-357

27. van Ginneken N, Maheedhariah MS, Ghani S, Ramakrishna J, Raja A, Patel V (2017) Human resources and models of mental healthcare integration into primary and community care in India: case studies of 72 programmes. PLoS ONE 12(6):e0178954

28. Organization WH (2013) Multi-country assessment of national capacity to provide hearing care. Switzerland, Geneva. Retrieved from: http://0-www.who.int.innopac.up.ac.za/pbd/publications/ WHOReportHearingCare_Englishweb.pdf. Accessed 1 Apr 2018

29. Nordin M, Hondras M, Outerbridge G, Kopansky-Giles D, Côté P, da Silva S et al (2016) Global forum: spine research and training in underserved, low and middle-income, culturally unique communities: the World Spine Care Charity Research Program's challenges and facilitators. JBJS 98(24):e110

30. Irving G, Neves AL, Dambha-Miller H, Oishi A, Tagashira H, Verho A et al (2017) International variations in primary care physician consultation time: a systematic review of 67 countries. BMJ Open 7(10): e017902

31. Visagie S, Schneider M (2014) Implementation of the principles of Primary Health Care in a rural area of South Africa. Afr J Prim health Care Fam Med 6(1):1-10

32. Goertz CM, Weeks WB, Justice B, Haldeman S (2017) A proposal to improve health-care value in spine care delivery: the primary spine practitioner. Spine J 17(10):1570-1574

33. Hartvigsen J, Foster NE, Croft PR (2011) We need to rethink front line care for back pain. BMJ 342

34. Scott N, Moga C, Harstall C (2010) Managing low back pain in the primary care setting: the know-do gap. Pain Res Manag 15(6):392-400

35. Prinja S, Balasubramanian D, Jeet G, Verma R, Kumar D, Bahuguna $P$ et al (2017) Cost of delivering secondary-level health care services through public sector district hospitals in India. Indian J Med Res 146(3):354

36. Prinja S, Bahuguna P, Pinto AD, Sharma A, Bharaj G, Kumar V et al (2012) The cost of universal health care in India: a model based estimate. PLoS ONE 7(1):e30362 
37. Ma X-M, Chen X-H, Wang J-S, Lyman GH, Qu Z, Ma W et al (2015) Evolving healthcare quality in top tertiary general hospitals in china during the china healthcare reform (2010-2012) from the perspective of inpatient mortality. PLoS ONE 10(12):e0140568

38. Kuhn EN, Warmus BA, Davis MC, Oster RA, Guthrie BL (2016) Identification and cost of potentially avoidable transfers to a tertiary care neurosurgery service: a pilot study. Neurosurgery 79(4):541-548

39. Shelton JD (2011) Twenty criteria to make the best of scarce health resources in developing countries. BMJ 343:d7023

40. Hwang W, Chang J, Laclair M, Paz H (2013) Effects of integrated delivery system on cost and quality. Am J Manag Care 19(5):e175-e184

41. Littlechild B, Smith R (2013) A handbook for interprofessional practice in the human services: learning to work together. Routledge, New York
42. Lemieux-Charles L, McGuire WL (2006) What do we know about health care team effectiveness? A review of the literature. Med Care Res Rev 63(3):263-300

43. Organization WH (2010) Framework for action on interprofessional education \& collaborative practice. World Health Organization, Geneva

44. Kim JS, Dong JZ, Brener S, Coyte PC, Rampersaud YR (2011) Cost-effectiveness analysis of a reduction in diagnostic imaging in degenerative spinal disorders. Healthc Policy 7(2):e105

45. Gimigliano F, Negrini S (2017) The World Health Organization "Rehabilitation 2030 — a call for action". Eur J Phys Rehabil Med 53(2):155-168

46. Haldeman S, Nordin M, Outerbridge G, Hurwitz EL, Hondras M, Kopansky-Giles D et al (2015) Creating a sustainable model of spine care in underserved communities: the World Spine Care (WSC) charity. Spine J 15(11):2303-2311

\section{Affiliations}

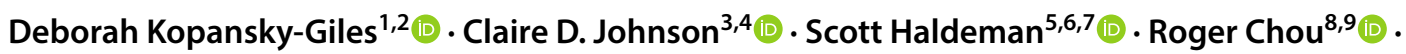
Pierre Côté ${ }^{10,11}$ (1) Bart N. Green ${ }^{3,4}$ (1) Margareta Nordin ${ }^{12,13}$ (I) Emre Acaroğlu ${ }^{14}$ (D) Arthur Ameis ${ }^{15}$ (1) Christine Cedraschi ${ }^{16,17}$ (1) Eric L. Hurwitz ${ }^{18}$ (D) Selim Ayhan ${ }^{19}$ (D) David Borenstein ${ }^{20}$ (1) O'Dane Brady ${ }^{21}$ (1) Peter Brooks ${ }^{22} \cdot$ Fereydoun Davatchi ${ }^{23}$ (1) $\cdot$ Robert Dunn ${ }^{24,25}$ (C) Christine Goertz ${ }^{26,27}$ (1) Najia Hajjaj-Hassouni ${ }^{28}$ (D)

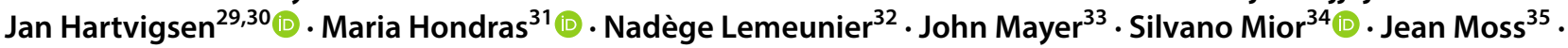
Rajani Mullerpatan ${ }^{36}$. Elijah Muteti ${ }^{37} \cdot$ Lillian Mwaniki $^{38} \cdot$ Madeleine Ngandeu-Singwe $^{39} \cdot$ Geoff Outerbridge $^{40}$ (1) . Kristi Randhawa ${ }^{10,11}$. Carlos Torres ${ }^{41,42} \cdot$ Paola Torres $^{43} \cdot$ Adriaan Vlok $^{44} \cdot$ Chung Chek Wong $^{45}$

Claire D. Johnson

globalspinecareinitiative@gmail.com

1 Department of Research, Canadian Memorial Chiropractic College, Toronto, ON, Canada

2 Department of Family and Community Medicine, University of Toronto, Toronto, ON, Canada

3 National University of Health Sciences, Lombard, IL, USA

4 Qualcomm Health Center, Stanford Health Care, San Diego, CA, USA

5 Department of Epidemiology, School of Public Health, University of California Los Angeles, Los Angeles, CA, USA

6 Department of Neurology, University of California, Irvine, Irvine, CA, USA

7 World Spine Care, Santa Ana, CA, USA

8 Department of Medical Informatics and Clinical Epidemiology, Oregon Health and Science University, Portland, OR, USA

9 Department of Medicine, Oregon Health and Science University, Portland, OR, USA

10 Faculty of Health Sciences, University of Ontario Institute of Technology, Oshawa, Canada

11 UOIT-CMCC Centre for Disability Prevention and Rehabilitation, Toronto, Canada

12 Departments of Orthopedic Surgery and Environmental Medicine, New York University, New York, NY, USA

13 World Spine Care Europe, Holmfirth, UK

14 ARTES Spine Center, Ankara, Turkey
15 Certification Program in Insurance Medicine and MedicoLegal Expertise, University of Montreal Faculty of Medicine, Toronto, ON, Canada

16 Division of General Medical Rehabilitation, Multidisciplinary Pain Centre, Geneva University Hospitals, Geneva, Switzerland

17 Division of Clinical Pharmacology and Toxicology, Multidisciplinary Pain Centre, Geneva University Hospitals, Geneva, Switzerland

18 Office of Public Health Studies, University of Hawai'I, Mānoa, Honolulu, HI, USA

19 ARTES Spine Center, Acibadem University, Ankara, Turkey

20 Arthritis and Rheumatism Associates, The George Washington University Medical Center, Potomac, MD, USA

21 World Spine Care, Tampa, FL, USA

22 Centre for Health Policy, School of Population and Global Health, University of Melbourne, Toorak, Melbourne, VIC, Australia

23 Rheumatology Research Center, Tehran University of Medical Sciences, Tehran, Tehran, Iran

24 Department of Orthopaedic Surgery, University of Cape Town, Cape Town, Western Cape, South Africa

25 Groote Schuur Hospital, Cape Town, Western Cape, South Africa

26 Palmer College of Chiropractic, Davenport, IA, USA

27 The Spine Institute for Quality, Davenport, IA, USA

28 Mohammed VI University of Health Sciences (UM6SS), Casablanca, Morocco 
29 Department of Sports Science and Clinical Biomechanics, University of Southern Denmark, Odense, Denmark

30 Nordic Institute of Chiropractic and Clinical Biomechanics, Odense, Denmark

31 Department of Anesthesiology, University of Kansas Medical Center, Kansas City, KS, USA

32 Institut Franco-Européen de Chiropraxie, Toulouse, France

33 U.S. Spine and Sport Foundation, San Diego, CA, USA

34 Canadian Memorial Chiropractic College, Toronto, ON, Canada

35 Canadian Memorial Chiropractic College, President Emerita, Toronto, ON, Canada

36 MGM School of Physiotherapy, Mahatma Gandhi Mission Institute of Health Sciences, Navi Mumbai, Maharashtra, India

37 Moi University/Moi Teaching and Referral Hospital, Eldoret, Kenya
38 Law Society of Kenya, Nairobi, Kenya

39 Faculty of Medicine and Biomedical Sciences, The University of Yaoundé I, Yaounde, Center Region, Cameroon

40 World Spine Care and Canadian Memorial Chiropractic College, Chelsea, QC, Canada

41 University of Ottawa, Ottawa, ON, Canada

42 Department of Medical Imaging, The Ottawa Hospital, Ottawa, ON, Canada

43 Exercise Science Laboratory, School of Kinesiology, Faculty of Medicine, Universidad Finis Terrae, Santiago, Chile

44 Division of Neurosurgery, University of Stellenbosch, Bellville, Western Cape, South Africa

45 Sarawak General Hospital, Kuching, Sarawak, Malaysia 